\title{
Absence of NOTCH1 gene mutations in MALT lymphomas
}

The NOTCH family of genes encodes a set of four transmembrane receptors that function in cell fate decisions during the development of many cell types, including B-cells, and recent studies have indicated an important oncogenic role for $\mathrm{NOTCH}$ activation in various B-cell malignancies (Mirandola et al, 2011). In particular, NOTCH signalling is known to be important for the generation of marginal zone B-cells (Hozumi et al, 2004; Santos et al, 2007). Three subtypes of lymphoma are believed to derive from marginal zone B-cells: splenic marginal zone lymphoma (MZL), nodal MZL and the more common extranodal MZL of mucosa-associated lymphoid tissue (MALT) (Swerdlow et al, 2008). NOTCH2 mutations have been reported in B-cell lymphomas, including MZL, albeit at a low frequency $(<5 \%)$ (Troen et al, 2008; Lee et al, 2009). Very recently, NOTCH1 mutations have been reported in chronic lymphocytic leukaemia (CLL) (Fabbri et al, 2011; Puente et al, 2011). These observations led us to examine the mutational status of NOTCH1 in a panel of MALT lymphomas. We focused on exon 34 of NOTCH1 as it is the most commonly targeted site for activating mutations that remove the C-terminal PEST domain, giving rise to a constitutively active and more stable NOTCH1 protein (Weng et al, 2004; Fabbri et al, 2011; Puente et al, 2011).

Twenty-three cases of MALT lymphomas were analysed. Informed consent was obtained in accordance with the Declaration of Helsinki following the procedures approved by the local ethical committees and institutional review boards of each participating institution. The sites of anatomical involvement were: orbital adnexa (eight cases), stomach (five), salivary glands (four), skin (four), thyroid, lung (one each). Seven cases presented involvement of multiple organs. DNA samples were obtained as previously described (Rinaldi et al, 2011). Whole genome-amplification (WGA) was performed using $10 \mathrm{ng}$ of DNA per sample and the REPLI-g Mini kit (Qiagen AG, Hombrechtikon, Switzerland). For polymerase chain reaction (PCR) amplification of exon 34 of NOTCH1, $5 \mu \mathrm{l}$ of WGA DNA was used with the following primers: 5'-TCCACCAGTTTGAATGGTCA-3' (forward) and 5'-AAGG CTTGGGAAAGGAAGC-3' (reverse). A Richter syndrome (RS) sample known to harbour a heterozygous CT deletion in exon 34 of NOTCH1 was included as a positive control (Fabbri et al, 2011). PCR products were purified using the QIAquick PCR purification kit (Qiagen AG) and Sanger sequencing of purified PCR products was performed (Microsynth AG, Balgach, Switzerland). Sequence chromatograms were viewed with 4Peaks Version 1.7.2 (Mekentosj, Aalsmeer, The Netherlands). All samples had been previously character- ized for copy number changes with Affymetrix Human Mapping $250 \mathrm{k}$ arrays (Affymetrix, Santa Clara, CA, USA) (Rinaldi et al, 2011).

None of the previously reported mutations affecting exon 34 nor any novel mutations were observed, while the heterozygous CT deletion recently reported as present in approximately $10 \%$ of B-cell CLL and $31 \%$ of RS was observed only in the RS sample included as a positive control, thereby supporting the methodology used. Also, the NOTCH1 locus was not a target of DNA gains, amplifications or copy neutral loss of heterozygosity in the 23 MALT lymphomas (nor in an additional 24 samples) analysed.

Together, these results suggest that activating mutations of NOTCH1 are not a common pathogenetic mechanism in MALT lymphomas. It is possible that targeting of other components of the NOTCH signalling pathway may be more relevant for MZL. Larger studies investigating other components of the NOTCH signalling pathway may shed more light on the precise contribution of NOTCH signalling to MALT pathogenesis and possibly open up new treatment avenues for MALT lymphomas.

\section{Acknowledgements}

Work supported by Oncosuisse grant OCS-02034-02-2007; Italian Association for Cancer Research (AIRC). We thank Miss Prisca Cima for her expert technical assistance.

\section{Authors contribution}

FB, DR and GG conceived and designed the study. AAM, AR performed experiments. MP, VC, SU, GB, DR, GG and EZ collected and characterized MZL samples. AAM and FB interpreted the co-wrote the manuscript. All authors read and approved the final manuscript.

\section{Conflict of Interest}

All authors declare no conflict of interest.

Afua Adjeiwaa Mensah
Andrea Rinaldi $^{1}$
Maurilio Ponzoni $^{2}$
Vincenzo Canzonieri $^{3}$
Silvia Uccella
Davide Rossi $^{5}$
Govind Bhagat $^{6}$

Afua Adjeiwaa Mensah ${ }^{1}$

Andrea Rinaldi ${ }^{1}$

Maurilio Ponzoni ${ }^{2}$

Vincenzo Canzonieri

Davide Rossi

Govind Bhagat ${ }^{6}$ 


\section{Gianluca Gaidano ${ }^{5}$ \\ Emanuele Zucca ${ }^{7}$ \\ Francesco Bertoni ${ }^{1,7}$}

${ }^{1}$ IOR-Institute of Oncology Research, IOSI-Oncology Institute of Southern Switzerland, Bellinzona, Switzerland, ${ }^{2}$ Unit of Lymphoid Malignancies, Department of Onco-Haematology, San Raffaele Scientific Institute, Milan, ${ }^{3}$ Division of Pathology, Centro di Riferimento Oncologico, I.R.C.C.S., Aviano (PN), ${ }^{4}$ Anatomic Pathology Unit, University of
Insubria, Ospedale di Circolo, Varese, ${ }^{5}$ Division of Haematology, Department of Clinical and Experimental Medicine and BRMA, Amedeo Avogadro University of Eastern Piedmont, Novara, Italy, ${ }^{6}$ Herbert Irving Comprehensive Cancer Center, Department of Pathology and Cell Biology, Columbia University Medical Center and New York Presbyterian Hospital, New York, NY, USA, and ${ }^{7}$ Lymphoma Unit, IOSI-Oncology Institute of Southern Switzerland, Bellinzona, Switzerland E-mail: frbertoni@mac.com

\section{References}

Fabbri, G., Rasi, S., Rossi, D., Trifonov, V., Khiabanian, H., Ma, J., Grunn, A., Fangazio, M., Capello, D., Monti, S., Cresta, S., Gargiulo, E., Forconi, F., Guarini, A., Arcaini, L., Paulli, M., Laurenti, L., Larocca, L.M., Marasca, R., Gattei, V., Oscier, D., Bertoni, F., Mullighan, C.G., Foa, R., Pasqualucci, L., Rabadan, R., Dalla-Favera, R. \& Gaidano, G. (2011) Analysis of the chronic lymphocytic leukemia coding genome: role of NOTCH1 mutational activation. The Journal of Experimental Medicine, 208, 1389-1401.

Hozumi, K., Negishi, N., Suzuki, D., Abe, N., Sotomaru, Y., Tamaoki, N., Mailhos, C., Ish-Horowicz, D., Habu, S. \& Owen, M.J. (2004) Delta-like 1 is necessary for the generation of marginal zone $\mathrm{B}$ cells but not T cells in vivo. Nature Immunology, 5, 638-644.

Lee, S.Y., Kumano, K., Nakazaki, K., Sanada, M., Matsumoto, A., Yamamoto, G., Nannya, Y., Suzuki, R., Ota, S., Ota, Y., Izutsu, K., Sakata-Yanagimoto, M., Hangaishi, A., Yagita, H., Fukayama, M., Seto, M., Kurokawa, M., Ogawa, S. \& Chiba, S. (2009) Gain-of-function mutations and copy number increases of Notch2 in diffuse large B-cell lymphoma. Cancer Science, 100, 920926.

Mirandola, L., Comi, P., Cobos, E., Kast, W.M., Chiriva-Internati, M. \& Chiaramonte, R. (2011)
Notch-ing from T-cell to B-cell lymphoid malignancies. Cancer Letters, 308, 1-13.

Puente, X.S., Pinyol, M., Quesada, V., Conde, L., Ordonez, G.R., Villamor, N., Escaramis, G., Jares, P., Bea, S., Gonzalez-Diaz, M., Bassaganyas, L., Baumann, T., Juan, M., Lopez-Guerra, M., Colomer, D., Tubio, J.M., Lopez, C., Navarro, A., Tornador, C., Aymerich, M., Rozman, M., Hernandez, J.M., Puente, D.A., Freije, J.M., Velasco, G., Gutierrez-Fernandez, A., Costa, D., Carrio, A., Guijarro, S., Enjuanes, A., Hernandez, L., Yague, J., Nicolas, P., Romeo-Casabona, C.M., Himmelbauer, H., Castillo, E., Dohm, J.C., de Sanjose, S., Piris, M.A., de Alava, E., San Miguel, J., Royo, R., Gelpi, J.L., Torrents, D., Orozco, M., Pisano, D.G., Valencia, A., Guigo, R., Bayes, M., Heath, S., Gut, M., Klatt, P., Marshall, J., Raine, K., Stebbings, L.A., Futreal, P.A., Stratton, M.R., Campbell, P.J., Gut, I., Lopez-Guillermo, A., Estivill, X., Montserrat, E., Lopez-Otin, C. \& Campo, E. (2011) Whole-genome sequencing identifies recurrent mutations in chronic lymphocytic leukaemia. Nature, 475, 101-105.

Rinaldi, A., Mian, M., Chigrinova, E., Arcaini, L., Bhagat, G., Novak, U., Rancoita, P.M., De Campos, C.P., Forconi, F., Gascoyne, R.D., Facchetti, F., Ponzoni, M., Govi, S., Ferreri, A.J., Mollejo, M., Piris, M.A., Baldini, L., Soulier, J., Thieblemont, C., Canzonieri, V., Gattei, V., Marasca, R., Franceschetti, S., Gaidano, G., Tucci,
A., Uccella, S., Tibiletti, M.G., Dirnhofer, S., Tripodo, C., Doglioni, C., Dalla Favera, R., Cavalli, F., Zucca, E., Kwee, I. \& Bertoni, F. (2011) Genome-wide DNA profiling of marginal zone lymphomas identifies subtype-specific lesions with an impact on the clinical outcome. Blood, 117, 1595-1604.

Santos, M.A., Sarmento, L.M., Rebelo, M., Doce, A.A., Maillard, I., Dumortier, A., Neves, H., Radtke, F., Pear, W.S., Parreira, L. \& Demengeot, J. (2007) Notch1 engagement by Delta-like-1 promotes differentiation of B lymphocytes to antibody-secreting cells. Proceedings of the $\mathrm{Na}$ tional Academy of Sciences of the United States of America, 104, 15454-15459.

Swerdlow, S.H., Campo, E., Harris, N.L., Jaffe, E.S., Pileri, A., Stein, H., Thiele, J. \& Vardiman, J.W. (eds) (2008) WHO Classification of Tumours of Haematopoietic and Lymphoid Tissues. IARC Press, Lyon, France.

Troen, G., Wlodarska, I., Warsame, A., Hernandez Llodra, S., De Wolf-Peeters, C. \& Delabie, J. (2008) NOTCH2 mutations in marginal zone lymphoma. Haematologica, 93, 1107-1109.

Weng, A.P., Ferrando, A.A., Lee, W., Morris, J.P.t., Silverman, L.B., Sanchez-Irizarry, C., Blacklow, S.C., Look, A.T. \& Aster, J.C. (2004) Activating mutations of NOTCH1 in human T cell acute lymphoblastic leukemia. Science, 306, 269-271. 